\title{
Evaluation of near surface ozone and particulate matter in air quality simulations driven by dynamically downscaled historical meteorological fields
}

\author{
Karl M. Seltzer ${ }^{\mathrm{a}, \mathrm{b}}$, Christopher G. Nolte ${ }^{\mathrm{a}, *}$, Tanya L. Spero ${ }^{\mathrm{a}}$, K. Wyat Appel ${ }^{\mathrm{a}}$, \\ Jia Xing ${ }^{a, c}$ \\ ${ }^{a}$ National Exposure Research Laboratory, U.S. Environmental Protection Agency, \\ Research Triangle Park, NC, 27711, USA \\ ${ }^{b}$ Nicholas School of the Environment, Duke University, Durham, NC, USA \\ ${ }^{c}$ School of Environment, Tsinghua University, Beijing, China
}

\begin{abstract}
In this study, techniques typically used for future air quality projections are applied to a historical 11-year period to assess the performance of the modeling system when the driving meteorological conditions are obtained using dynamical downscaling of coarse-scale fields without correcting toward higher-resolution observations. The Weather Research and Forecasting model and the Community Multiscale Air Quality model are used to simulate regional climate and air quality over the contiguous United States for 2000-2010. The air quality simulations for that historical period are then compared to observations from four national networks. Comparisons are drawn between defined performance metrics and other published modeling results for predicted ozone, fine particulate matter, and speciated fine particulate matter. The results indicate that the historical air quality simulations driven by dynamically downscaled meteorology are typically within defined modeling performance benchmarks and are consistent with results from other published modeling studies using finer-resolution meteorology. This indicates that the regional climate and air quality modeling framework utilized here does not introduce substantial bias, which provides confidence in the method's use for future air quality projections.
\end{abstract}

\footnotetext{
* Corresponding author

Email address: nolte.chris@epa.gov (Christopher G. Nolte)
}

Preprint submitted to Elsevier

April 25, 2016 
Keywords: air quality, dynamic downscaling, model evaluation, climate change, CMAQ

\section{INTRODUCTION}

Air quality is strongly influenced by meteorology, and it is well established that a changing climate will affect future ambient air quality (e.g., Jacob and Winner, 2009; Weaver et al., 2009; Fiore et al., 2015). Many studies that have examined the effects of climate change on air quality have concluded that surface ozone $\left(\mathrm{O}_{3}\right)$ levels will likely increase in localized areas due to the projected changes in meteorological conditions (Leung and Gustafson, 2005; Nolte et al., 2008; Katragkou et al., 2011; Kelly et al., 2012; Trail et al., 2014; Fann et al., 2015). This has potential implications for air quality management plans, because the "climate penalty" (Wu et al., 2008) may offset some of the improvements in ambient air quality that would otherwise occur as emissions controls are implemented (Fann et al., 2016), with adverse consequences for human health. One other potential effect of climate change on air quality is a regionally dependent lengthening of the ozone season, historically classified as May through September in most of the United States (e.g., Fiore et al., 2002; Nolte et al., 2008; Weaver et al., 2009; Cooper et al., 2014; Clifton et al., 2014). Accordingly, it is critical to develop a regional modeling framework that can credibly project air quality changes resulting from future climate scenarios.

For most historical ("retrospective") regional air quality studies using Eulerian models, meteorological conditions are obtained from a comparably scaled meteorological model. Furthermore, the meteorology developed for those retrospective air quality modeling applications assimilates observations where available to achieve the best possible representation of the three-dimensional evolution of the meteorological conditions over the time period of interest (Otte, 2008a,b). Several "dynamic evaluation" air quality modeling studies have been conducted in which the focus is not the air quality model's predictions in comparison to observations, but rather on the model's response to changing emis- 
sions or meteorology (e.g., Gilliland et al., 2008; Foley et al., 2015). Hogrefe et al. (2011) conducted an 18-year simulation over the Northeast United States, examining the model's ability to capture the interannual variability in $\mathrm{O}_{3}$ levels due to meteorology as well as trends due to changes in emissions. In all of these studies, the meteorology was developed by assimilating high-resolution observational data.

When starting from a coarse-scale global modeling framework to simulate regional-scale air quality, dynamical downscaling can be used (Giorgi and Meleux, 2007). In dynamical downscaling, the coarse global data provide input to the regional model through the lateral boundaries and sometimes within the interior domain through "nudging". Interior nudging maintains consistency in the weather patterns between the global and regional models and can reduce errors in the regional model (von Storch et al., 2000; Miguez-Macho et al., 2004; Bowden et al., 2012). Unlike traditional retrospective meteorological modeling, no fine-scale observations are assimilated when downscaling. It is challenging, however, to evaluate the effects of using meteorology downscaled from a global climate model (GCM) for simulating air quality. Fields from a GCM are representative of the climate during that era, e.g., "climate circa 2000," but cannot accurately simulate the weather of the day. It is therefore necessary to model several years to account for interannual variability of meteorological conditions. Also, air pollutant emissions have been changing dramatically over the past few decades, and it is necessary to consider these changes when comparing to measurements taken over multiple years.

In order to evaluate the validity of using downscaled fields to drive future air quality projections, it is important to test the downscaling method using historical coarse-scale global fields without correcting toward higher-resolution meteorological observations. The downscaled meteorology may then be used to drive a chemical transport model, and the results can be compared to historical observations of air quality to ascertain whether future air quality projections based on downscaled meteorology can provide credible results. Only a few studies have been conducted using dynamically downscaled historical meteorology 
to simulate regional air quality, all of which were focused on Europe (Katragkou et al., 2010; Zanis et al., 2011; Lacressonnière et al., 2012; Menut et al., 2013). Meteorological variables important for simulating air quality, including temperature, precipitation, boundary layer height, and wind speeds, can be degraded when the regional model is driven by dynamically downscaled meteorology (Katragkou et al., 2010; Lacressonnière et al., 2012; Menut et al., 2013). Katragkou et al. (2010) and Zanis et al. (2011) used meteorology downscaled from both the ECMWF ERA40 reanalysis and from the ECHAM5 global climate model to simulate European ozone concentrations over the decade 1991-2000. Katragkou et al. (2010) found that the modeling system adequately reproduced average decadal surface ozone levels at rural monitoring sites, while Zanis et al. (2011) reported that the performance of their modeling system using downscaled meteorology was comparable to that obtained in previous evaluation experiments. Lacressonnière et al. (2012) used both operational meteorological analyses and global climate model data to simulate European air quality, and found that the air quality model driven by climate model data was less skillful in reproducing air pollutant concentrations. However, the differences in model performance indicators between the two frameworks were not substantial, and they concluded that predictions driven by the climate model were adequate to simulate future European pollutant levels and associated health impacts. These studies generally did not consider changing emissions either within the modeling domain or the resulting influence on lateral boundary conditions. As a model sensitivity experiment, Katragkou et al. (2010) found that differences due to plausible changes in chemical boundary conditions were comparable to biases attributable to using meteorology from ECHAM5 rather than ERA40.

In this study, we conduct an 11-year simulation of air quality in the United States and evaluate model performance driven by downscaled historical meteorological fields that are not enhanced with high-resolution meteorological observations. The downscaled meteorology used here is meant to emulate the coarseness (in space and time) of a future climate scenario provided by a GCM. Year-specific emission estimates are used to capture the large changes in var- 
ious precursor emissions that occurred in the United States over the modeled years both within the United States (Xing et al., 2013) and globally (European Commission, 2011). The resulting air quality fields for the historical period are compared against observations from four national networks. Biases in ozone $\left(\mathrm{O}_{3}\right)$, total fine particulate matter $\left(\mathrm{PM}_{2.5}\right)$, and speciated fine particulate matter, including sulfate $\left(\mathrm{SO}_{4}{ }^{2-}\right)$, ammonium $\left(\mathrm{NH}_{4}{ }^{+}\right)$, nitrate $\left(\mathrm{NO}_{3}{ }^{-}\right)$, and organic carbon (OC), are compared to results typically attained in retrospective air quality model simulations forced by high-resolution, observation-driven dynamic analyses of the meteorological conditions. To our knowledge this work is the longest and most comprehensive air quality modeling study conducted to date using downscaled historical meteorology over the continental United States.

\section{MODELING CONFIGURATION}

The meteorology used for this study was generated by the Weather Research and Forecasting (WRF) model (Skamarock and Klemp, 2008) version 3.4.1. North America was modeled using a two-way nested 108-36-km configuration and 34 vertical layers up to $50 \mathrm{hPa}$. WRF was driven by $2.5^{\circ} \times 2.5^{\circ}$ reanalyses from the National Centers for Environmental Prediction-Department of Energy Atmospheric Model Intercomparison Project ("R2") (Kanamitsu et al., 2002). WRF was initialized 00 UTC 2 December 1987 and run continuously through the end of 2010. The physics options in WRF followed Otte et al. (2012), except the present study used the Kain-Fritsch subgrid cloud parameterization with radiative feedbacks (Herwehe et al., 2014). The U.S. Geological Survey (UGSG) 24-category land use classification was used. The Meteorology-Chemistry Interface Processor (Otte and Pleim, 2010) v4.2 was used to prepare WRF outputs for CMAQ.

In WRF, two variants of nudging are available for gridded fields: analysis nudging (or grid nudging) and spectral nudging. Analysis nudging is typically used for retrospective air quality modeling applications with WRF (Otte, 2008a,b), and it is appropriate because observations can be incorporated into 
the fields that are nudged so that they represent the spatial scales well. Spectral nudging (von Storch et al., 2000; Miguez-Macho et al., 2004) is often preferred by the regional climate modeling community because observations are not available in future climate scenarios and spectral nudging can be used to preserve the characteristics of the large-scale flow. See, for example, comparisons of analysis nudging and spectral nudging within WRF by Liu et al. (2012), Bowden et al. (2012, 2013), Otte et al. (2012), and Omrani et al. (2013). In this study we employed spectral nudging at all levels above the planetary boundary layer (Otte et al., 2012) of potential temperature, U- and V-component winds, and geopotential toward the R2 fields. No finer-scale observational data exogenous to the R2 were assimilated during the simulation.

The anthropogenic emissions used in this study were described by Xing et al. (2013). Activity data reported by the State Energy Data System were multiplied by emission factors derived from the U.S. Environmental Protection Agency (EPA) National Emissions Inventory (NEI) and constrained by AP-42 emission control factors. This dataset accounts for various emission drivers, such as population, economic growth, and historical pollutant controls. Simply using the NEI, which is considered to be the hallmark of emissions datasets for the United States, was not an option in our 11-year simulation for two reasons. First, the NEI emission profiles are updated every three years. Therefore, emissions in the NEI often do not account for fluctuating economic drivers which can strongly dictate emission levels between reporting years. Second, the methodology to develop the NEI evolves with each release, leading to inconsistencies that make their use in multi-year simulations problematic (Xing et al., 2013). Biogenic emissions were calculated within CMAQ and responded to changes in the meteorological conditions.

Air quality was simulated using the Community Multiscale Air Quality (CMAQ) model version 5.0.2 (Byun and Schere, 2006; Appel et al., 2013), with a 36-km domain subset from the WRF 36-km North American domain and spanning the continental United States. The CMAQ simulation used the same USGS land use classification and 34-layer vertical structure as the WRF simulation. 
CMAQ was configured with the Carbon Bond 2005 gas phase mechanism with updates for toluene and chlorine chemistry (CB05TUCL; Sarwar et al., 2011), the AERO6 aerosol module (Simon and Bhave, 2012; Appel et al., 2013; Nolte et al., 2015), and online calculation of photolysis rates (Foley et al., 2010). Initial and lateral boundary conditions for CMAQ originated from a 108-km CMAQ simulation that encompassed the Northern Hemisphere (Xing et al., 2015). An initial spin-up of ten days was conducted, followed by 11 years of continuous simulations, spanning 1 January 2000 through 31 December 2010.

Retrospective air quality studies for continental-scale domains over annual or shorter periods using regional-scale models like WRF and CMAQ typically use higher spatial resolution than the $36-\mathrm{km}$ grid spacing used here. For example, Foley et al. (2010), Appel et al. (2011, 2013), and Nolte et al. (2015) all employed 12-km grid spacing, while studies in California typically use grid spacings of 4-5 km (Ying and Kleeman, 2006) to represent accurately the meteorological flow in complex terrain and the strong spatial gradients in emissions. However, simulations to assess air quality trends (Hogrefe et al., 2011; Gan et al., 2016) or the influence of climate change on air quality (Nolte et al., 2008; Gao et al., 2013; Trail et al., 2014; Gonzalez-Abraham et al., 2015) must be run for multiple years and require intense computational resources that make it impractical to use as fine a horizontal grid spacing. For this reason, 36-km modeling is commonly used to examine health impacts under a changing climate (Bell et al., 2007; Post et al., 2012; Fann et al., 2015; Wilson et al., 2016). Gan et al. (2016) reported that the largest differences in PM concentrations simulated using $36-\mathrm{km}$ and 12-km model configurations were episodic, while differences in long-term trends were small. The results of Gan et al. (2016) further justify the use of $36-\mathrm{km}$ grid spacing, since most studies of the health effects of changes in air quality attributable to climate change are based on long-term average concentrations.

\section{EVALUATION FRAMEWORK}

Hourly $\mathrm{O}_{3}$ observations from EPA's Air Quality System (AQS) were processed into maximum daily 8-h average concentrations (MDA8), for comparison 
to the U.S. National Ambient Air Quality Standard (NAAQS). $\mathrm{PM}_{2.5}$ concentrations were obtained from the Chemical Speciation Network (CSN), the Clean Air Status and Trends Network (CASTNet), and the Interagency Monitoring of Protected Visual Environments (IMPROVE) network. Total $\mathrm{PM}_{2.5}$ is evaluated, as are its most abundant speciated components: sulfate $\left(\mathrm{SO}_{4}{ }^{2-}\right)$, ammonium $\left(\mathrm{NH}_{4}^{+}\right)$, nitrate $\left(\mathrm{NO}_{3}^{-}\right)$, and organic carbon (OC). AQS and CSN are primarily urban networks, with monitors generally located near populated regions. In contrast, CASTNet and IMPROVE are largely rural networks. The spatial distributions of the $\mathrm{O}_{3}$ and PM monitoring networks are shown in Fig. 1. Although there are differences in the testing and acceptance protocols among the networks, these differences minimally impact the measurements due to stringent quality assurance procedures (Solomon et al., 2014) and are neglected for this analysis. Additionally, it should be noted that some network monitors operate only seasonally, and that some monitors came online or went offline during the 11-year simulation period. All available measurements reported by each network over the modeling period are used in these calculations. Accordingly, the number of sites in each network that are included in the analysis vary slightly by year and season.

Modeled values are taken from the grid cells and time periods corresponding to the observations. The model evaluation metrics used in this study are mean bias (MB), mean error (ME), mean fractional bias (MFB), and mean fractional error (MFE), as defined in Table 1. The MFB and MFE are normalized by the mean of each model-observation pair, and therefore do not assume that the observations are the absolute truth. Additionally, the MFB and MFE have the advantage of being bounded, symmetric metrics, meaning that they give equal weight to modeled concentrations greater than observations and to modeled concentrations less than observations, and are not unduly influenced by a few instances where the observations in the denominator are very low (Yu et al., 2006).

Boylan and Russell (2006) proposed a PM model evaluation framework using specified "goal" and "criteria" values for MFB and MFE, reproduced in Table 1. 
These definitions qualitatively classify model performance within three zones: (1) meeting the goal; (2) failing the goal but meeting the criteria; and (3) failing to meet either the goal or the criteria. According to Boylan and Russell (2006), the modeling goal is "considered to be close to the best a model can be expected to achieve." If the model performance satisfies the criteria but fails to meet the goal, the results are still considered acceptable. If neither the goal nor the criteria is met, the performance is outside the range of what is considered acceptable. Note that the Boylan and Russell (2006) specifications allow for greater relative error at lower concentrations. Conversely, at higher concentrations, the MFB goal and criteria asymptotically approach $30 \%$ and $60 \%$, respectively, while the MFE goal and criteria asymptotically approach $50 \%$ and $75 \%$, respectively. Following Boylan and Russell (2006), we assess the model performance for each constituent at each network on a monthly basis.

Finally, the results from this study are compared to other published air quality modeling studies. The main source for this comparison is Simon et al. (2012), who compiled statistical results from 69 contemporary modeling evaluations conducted between 2006 and 2012.

\section{RESULTS}

\subsection{Meteorology}

Since meteorological fields strongly influence the simulation of air quality, an analysis of the meteorological input to the CMAQ simulations is conducted here. Only a brief analysis of the meteorology is provided because the focus of this paper is on the performance of the air quality simulations. The $36-\mathrm{km}$ downscaled meteorological fields simulated by WRF are compared against hourly $0.31^{\circ}$ fields from the Climate Forecast System Reanalysis (CFSR) (Saha et al., 2010) for 2-m temperature and against three-hourly 32-km North American Regional Reanalysis (NARR) (Mesinger et al., 2006) fields for precipitation. Regionally averaged monthly deviations in the downscaled WRF simulations from CFSR and NARR are shown in Fig. 2 for the 11-year historical period, 2000-2010, which was used for the CMAQ simulations in this analysis. Monthly average 
temperature differences across the United States have a cool bias of up to $2 \mathrm{~K}$. The 2-m temperatures have very high correlations (0.997-0.999), which is typical for modeling diurnal and annual cycles with WRF, and the monthly mean bias in 2-m temperature ranges from -1.2 to $-0.3 \mathrm{~K}$ within the six regions. The WRF simulation also has a wet bias of $0-40 \mathrm{~mm} \mathrm{mon}^{-1}$, and the mean regional bias in precipitation ranges from $11.0 \mathrm{~mm} \mathrm{mon}^{-1}$ in the Southeast to $37.2 \mathrm{~mm} \mathrm{mon}^{-1}$ in the Northeast. As expected, the precipitation correlation coefficient with respect to NARR is lower for precipitation than for temperature, ranging from 0.796 in the Southeast to 0.933 in the Northwest. The correlations in precipitation tend to be higher in regions that are dominated by large-scale precipitation and lower in regions that are dominated by convective precipitation.

The levels of bias in temperature and precipitation in this WRF simulation are consistent with those obtained for 1988-2007 using a similar configuration of WRF with spectral nudging (see simulation "SN" in Figs. 4-6 of Otte et al. (2012) and Fig. 3 of Spero et al. (2014)). A comprehensive evaluation of that SN simulation appears in Otte et al. (2012), where means, variability, and extremes in meteorological fields over a 20-year period are simulated with reasonable accuracy. The regional correlation coefficients and mean biases in Fig. 2 of the present study are comparable to the SN simulation shown in Fig. 3 of Spero et al. (2014), which provides confidence that the WRF fields are of sufficient quality to be used in driving a CMAQ simulation.

\subsection{Ozone}

To examine air quality, we first compare the central portion of the observed and modeled $\mathrm{O}_{3}$ distributions. Figure 3 shows the interquartile range (IQR, i.e., the 25th-75th percentiles) of the observed and modeled MDA8 $\mathrm{O}_{3}$ concentrations for each season and year from 2000 to 2010. A few trends are apparent in the observed MDA8 $\mathrm{O}_{3}$ levels throughout this period. First, the observations show a decreasing trend in the 75 th percentile summer (JJA) $\mathrm{O}_{3}$. Also evident is an increasing trend in 25 th percentile winter (DJF) values. These trends were 
discussed by Cooper et al. (2014) and Simon et al. (2015), with both attributing these trends primarily to recent declines in precursor $\mathrm{NO}_{\mathrm{x}}$ emissions in the U.S. over this time period.

The median modeled MDA8 $\mathrm{O}_{3}$ is essentially unbiased during the spring (MAM), but is positively biased by approximately $10 \mathrm{ppb}$ during the summer and fall (SON) and by around $7 \mathrm{ppb}$ during the winter. Despite this positive bias, CMAQ accurately captures the summer and winter $\mathrm{O}_{3}$ trends, responding to the decreasing precursor emissions, as well as interannual meteorological variability, as shown by the anomalously low observed and modeled $\mathrm{O}_{3}$ levels during the summer of 2004. The spread in the distribution (as represented by the magnitude of the IQR, or the height of the bars in Fig. 3) is well simulated by the model for the summer, but is slightly compressed relative to the observations for spring and fall, and is substantially underrepresented during the winter. Additionally, the biases in the 25th percentiles, medians, and 75 th percentiles for each season show consistency from year to year (Table 2). The standard deviation of the bias in each percentile is less than the absolute average, providing coefficients of variation consistently below 1 , indicating low variability.

Simon et al. (2012) analyzed CMAQ predictions from Appel et al. (2011) and calculated the mean bias for four regions of the U.S. over the May-September $\mathrm{O}_{3}$ season between 2002 and 2006. The median of their mean bias calculations was positive 2.9 ppb. Across the modeling studies compiled by Simon et al. (2012), the IQR of $\mathrm{O}_{3}$ mean bias spanned approximately $0-6 \mathrm{ppb}$, with the upper end of the distribution extending to about $14 \mathrm{ppb}$. As shown in Table 3, the annual mean biases in the present study, when considering all seasons, range from 5.8$8.0 \mathrm{ppb}$, at or slightly above the Simon et al. (2012) 75th percentile but well within the range of prior studies. Eder and $\mathrm{Yu}(2006)$ reported an $\mathrm{MDA} 8 \mathrm{O}_{3}$ NMB of $8.1 \%$ and NME of $19.6 \%$ for April-September 2001. Here, the analogous statistics for the same modeled period were $14 \%$ and $23 \%$, respectively. The IQR of NMB and NME reported by Simon et al. (2012) spanned approximately 0-8\% and 15-22\%, respectively, with the distributions extending to $20 \%$ and $32 \%$. For the 11-year period in the present study, annual NMB and NME values 
range from $14-17 \%$ and $22-25 \%$, respectively. Again, these are higher than the 75th percentiles from the Simon et al. (2012) compilation, but are within their reported range.

CMAQ generally underestimates the dynamic range of $\mathrm{O}_{3}$ concentrations compared to measurements, with a positive bias at the low end of the distribution, a negative bias at the high end of the distribution, and performing best at predicting mid-range $\mathrm{O}_{3}$ levels (Foley et al., 2010; Simon et al., 2012). Additionally, U.S. EPA modeling guidance for $\mathrm{O}_{3}$ attainment demonstration (U.S. EPA, 2007) suggests excluding data points where the observed MDA8 $\mathrm{O}_{3}$ falls below a specified minimum threshold, due to the high frequency of low $\mathrm{O}_{3}$ concentrations and the greater relevance of higher values for human health and NAAQS compliance. Accordingly, model performance statistics for each yearly dataset were recalculated after applying thresholds of $60 \mathrm{ppb}$, corresponding to a moderate level of $\mathrm{O}_{3}$, and $70 \mathrm{ppb}$, equal to the 2015 revised NAAQS. Table 3 shows improved model performance statistics for higher $\mathrm{O}_{3}$ concentrations. When a $60 \mathrm{ppb}$ threshold is applied, the model bias is slightly negative ( $\mathrm{MB}=-1.2$ ppb; $\mathrm{MFB}=-2.7 \%$ ), and with a 70 ppb threshold, the model is more strongly negatively biased $(\mathrm{MB}=-4.2 \mathrm{ppb} ; \mathrm{MFB}=-6.4 \%)$. In comparison, Simon et al. (2012) reported larger negative biases at high $\mathrm{O}_{3}$ levels: the median bias and median fractional bias were $-4.95 \mathrm{ppb}$ and $-7.6 \%$ when using a $60 \mathrm{ppb}$ threshold and $-9.0 \mathrm{ppb}$ and $-12.3 \%$ when using a $75 \mathrm{ppb}$ threshold. Thus, the somewhat higher positive bias of the model configuration used in this study results in lower biases at the higher end of the $\mathrm{O}_{3}$ distribution.

\section{3. $P M_{2.5}$}

Figures 4 and 5 show the IQR of the observed and modeled total $\mathrm{PM}_{2.5}$ concentrations for each season and year from 2000 to 2010 for the CSN and IMPROVE sites, respectively. CASTNet is not included in this portion of the analysis since it does not report total $\mathrm{PM}_{2.5}$ concentrations. Observed concentrations at CSN sites are highest during the summer and winter and lowest during the spring. Median concentrations show a negative decadal trend for 
all seasons except spring, while there is a strong decline in 75 th percentile concentrations during the fall and winter. Modeled $\mathrm{PM}_{2.5}$ concentrations at CSN sites are negatively biased throughout the year, with the largest negative bias during the summer, which has been attributed to underpredictions of secondary organic aerosol (Carlton et al., 2010; Nolte et al., 2015). Despite the negative bias, however, Fig. 4 shows that the model captures both the declining decadal trends in medians and the interannual variability. The distribution of modeled values in the spring features almost no bias and is the best predicted season.

Relative to measurements at the more urban CSN sites, $\mathrm{PM}_{2.5}$ concentrations at IMPROVE sites are lower throughout the year. As with CSN, concentrations in the IMPROVE network are highest during the summer. Unlike observations at CSN locations, however, Fig. 5 shows little to no trend in median concentrations, with the possible exception of a negative summer trend since 2007. The absence of a negative trend is attributable to the fact that IMPROVE sites are primarily in the western U.S., while the majority of the $\mathrm{NO}_{\mathrm{x}}$ and $\mathrm{SO}_{2}$ emissions reductions have occurred in the eastern U.S. Modeled concentrations are slightly positively biased during the winter and negatively biased the rest of the year, with the negative bias largest during the summer. The magnitude of the IQR is well simulated during spring and fall, but is underestimated during summer and overestimated during winter.

Total $\mathrm{PM}_{2.5}$ MFB and MFE model performance statistics are presented in Fig. 6 in comparison to the Boylan and Russell (2006) curves. For these "bugle plots", statistics are computed on a monthly basis, resulting in 132 data points (11 modeled years $\times 12$ months per year) for each monitoring network. The model always meets the less-stringent criteria for both MFB and MFE, and it often meets the goal. Also evident in Fig. 6 are the higher concentrations across the CSN sites in comparison to IMPROVE.

The same model evaluation methods are also carried out for the major $\mathrm{PM}_{2.5}$ components at the CSN, IMPROVE, and CASTnet sites, when available. As shown in the bugle plots for sulfate, nitrate, ammonium, and organic carbon (Fig. 7), model performance varies by constituent and network. Performance is 
best for sulfate, which usually meets the performance goal for both MFB and MFE across all three networks. The goal is not met for only a few data points from CSN sites, where the model negative bias is too large, but the results still comfortably satisfy the performance criteria. The model also generally performs well for ammonium, always satisfying the performance criteria and nearly always satisfying the goal, particularly at CASTNet locations where the concentrations are lower. For CSN sites, however, the negative bias in ammonium concentrations is sometimes large enough to cause the MFB and MFE to fail the model performance goal, though the criteria is met.

Nitrate performs somewhat worse than sulfate and ammonium, with more points falling outside the MFB and MFE performance goals and a few failing to meet the performance criteria. Model performance is further degraded for organic carbon, which consistently underpredicts when observed concentrations exceed $3 \mu \mathrm{g} \mathrm{m}^{-3}$, resulting in MFB and MFE values that frequently do not meet the performance goal and often do not meet the performance criteria. Similar performance for OC was reported by Boylan and Russell (2006) in their original application of this evaluation method.

Figure 8 expands on the analysis by comparing the distribution of monthly MFB and MFE statistics for total $\mathrm{PM}_{2.5}$ and its constituents from this study to the results from other contemporary modeling studies summarized in Simon et al. (2012). Boxes show the IQR of monthly MFB and MFE computed across all modeled years, with the whiskers on each box extending to the 10th and 90th percentiles. It should be noted that MFB improves as the absolute value approaches zero. The distribution of monthly MFB in this study was comparable to the distribution in Simon et al. (2012), or better. The median MFB at CSN locations was $-16.8 \%$ and $-6.9 \%$ at IMPROVE locations. The median MFB reported in Simon et al. (2012) for total $\mathrm{PM}_{2.5}$ was $-12.0 \%$, with their IQR spanning -33.5 to $-3.0 \%$. As seen in the bottom panel of Fig. 8, the IQR of the MFE values for total $\mathrm{PM}_{2.5}$ from this study were $42.5-48.9 \%$ at CSN locations and 44.1-51.1\% at IMPROVE locations. In comparison, the IQR of the median MFE in Simon et al. (2012) was 34.0-54.0\%. 
Also shown in Fig. 8 are the IQR of the speciated $\mathrm{PM}_{2.5} \mathrm{MFB}$ and MFE results from this study for each of the observation networks and the results compiled in Simon et al. (2012). The IQR of the MFB results in this study is generally comparable to or better than the results from contemporary retrospective modeling studies for sulfate, ammonium, nitrate, and organic carbon. An exception is for organic carbon predictions at CSN sites, which is more strongly underpredicted in this study. However, the results are comparable when considering the 10th and 90th percentile results from Simon et al. (2012). Also included in Fig. 8 is the IQR of the MFE for the same datasets. The MFE for sulfate and nitrate perform well, while ammonium and organic carbon feature slightly higher IQR values of MFE at CSN sites, when compared to Simon et al. (2012). As previously discussed, the speciated portions of $\mathrm{PM}_{2.5}$ that were simulated most poorly, according to the Boylan and Russell (2006) performance metrics, were nitrate and organic carbon. The results in Fig. 8 indicate that the regional climate and air quality modeling framework used in this study produces levels of MFB and MFE for nitrate and organic carbon at levels consistent with other published studies.

\section{DISCUSSION AND CONCLUSIONS}

Historical $2.5^{\circ} \times 2.5^{\circ}$ global meteorological reanalyses from R2 were used as a proxy for a GCM and downscaled to $36-\mathrm{km}$ resolution using the WRF model. The WRF simulations were constrained using spectral nudging toward the R2, but were intentionally run without assimilating fine-scale observations, because such observations are not available to constrain regional climate simulations for future periods. The downscaled meteorological fields from WRF were then used to drive CMAQ for an 11-year period to evaluate the effects of these downscaling techniques on the simulated concentrations of various pollutants. The analysis of air quality focused on $\mathrm{O}_{3}$, total $\mathrm{PM}_{2.5}$, and speciated fine PM, including sulfate, ammonium, nitrate, and organic carbon. Concentrations simulated by CMAQ were compared against data from four national networks spanning the continental United States. These networks included the 
AQS, CSN, IMPROVE, and CASTNet monitoring sites. The modeling period spanned 2000-2010, which also corresponded with significant decreases across the U.S. in precursor emissions for $\mathrm{O}_{3}$ and $\mathrm{PM}_{2.5}$ (U.S. EPA, 1998; Xing et al., 2013). This signal was evident in statistical measures of pollutant levels at the monitoring sites used in this study.

Seasonal $\mathrm{O}_{3}$ trends were well simulated by this regional climate and air quality modeling configuration. CMAQ simulated the decrease in 75 th percentile summer $\mathrm{O}_{3}$ and the increase in 25 th percentile winter $\mathrm{O}_{3}$. In addition to capturing the overall $\mathrm{O}_{3}$ trends, CMAQ was able to maintain consistent bias between the observed and modeled percentiles. Analysis was also performed in which we excluded data points where observations were below a specified threshold, to analyze how CMAQ performed in simulating higher levels of $\mathrm{O}_{3}$, which are of most concern for human health and NAAQS compliance. After applying thresholds of $60 \mathrm{ppb}$ and $70 \mathrm{ppb}$ to the observed data, mean model bias from all years simulated dropped to $-1.2 \mathrm{ppb}$ and $-4.2 \mathrm{ppb}$, respectively. After applying a $60 \mathrm{ppb}$ and a $75 \mathrm{ppb}$ threshold to a previous CMAQ study, Simon et al. (2012) reported a median model bias of $-4.95 \mathrm{ppb}$ and $-12.3 \mathrm{ppb}$, respectively. However, the median model bias from their complete analysis was $2.9 \mathrm{ppb}$ while the mean model bias from the present study was $6.8 \mathrm{ppb}$. This indicates that the regional climate and air quality modeling configuration used here simulates somewhat higher levels of $\mathrm{O}_{3}$ when compared to other published air quality modeling results, but these higher levels actually improve CMAQ's negative bias at the higher end of the $\mathrm{O}_{3}$ concentration distribution.

Observations of total $\mathrm{PM}_{2.5}$ also showed some negative trends over the modeling period, particularly a decrease in 75th and 50th percentile concentrations during the fall and winter months at CSN sites. Total $\mathrm{PM}_{2.5}$ concentrations at IMPROVE network locations featured only a modest negative trend during the summer. CMAQ was negatively biased at CSN sites, with the largest absolute bias occurring in the summer when the concentrations were highest. At IMPROVE sites, CMAQ was typically biased low. An exception was during winter months, when the three analyzed percentiles of the modeled results were 
positively biased compared to the same percentiles of the observations. When evaluating the predicted total $\mathrm{PM}_{2.5}$ concentrations using the performance metrics of Boylan and Russell (2006), the results demonstrate that this modeling configuration is capable of simulating total $\mathrm{PM}_{2.5}$ concentrations at levels "considered to be close to the best a model can be expected to achieve." The results from this study were also comparable to the results from other contemporary modeling studies. The median monthly MFB from this study spanned $-4.1 \%$ to $-24.7 \%$ at CSN sites and $0.6 \%$ to $11.2 \%$ at IMPROVE sites while the median MFB from the Simon et al. (2012) compilation study was $12.0 \%$.

As expected, some components of $\mathrm{PM}_{2.5}$ were predicted better than others. Of the evaluated components, which included sulfate, ammonium, nitrate, and organic carbon, model performance was best for sulfate and ammonium, which typically met the modeling goals for mean fractional bias and mean fractional error and always met the modeling criteria. Inter-network trends also existed for these two components. For example, while the average observed concentrations of sulfate and ammonium were comparable at CSN and CASTNet locations, the levels of MFE at CASTNet locations for both these components were typically lower.

Nitrate and organic carbon were not predicted as well as sulfate and ammonium by CMAQ. Both components featured individual months during the 11year period where the MFB and MFE statistics failed to meet the performance criteria. Aerosol nitrate is principally formed via condensation of gas-phase nitric acid $\left(\mathrm{HNO}_{3}\right)$. The amount of nitrate in the particle phase depends not only on the amount of total nitrate available, but also on the concentrations of other species, including sulfate and ammonium, as well as temperature and relative humidity. As a consequence, nitrate concentrations are particularly challenging to simulate accurately ( $\mathrm{Yu}$ et al., 2005). Nitrate is also difficult to measure, as it is subject to revolatilization from a filter during sampling. For organic carbon, it has been previously reported that CMAQ frequently underestimates its mass, particularly in summer months (Carlton et al., 2010). To determine whether these levels of model bias for nitrate and organic carbon were attributable to 
using downscaled meteorology or represented typical levels of bias, the MFB and MFE results from this study were again compared to the results from the Simon et al. (2012) compilation study. The results demonstrate that the MFB and MFE levels in this study were generally comparable to results from other air quality studies, except organic carbon at the typically urban CSN sites, where it was further underestimated.

The results demonstrate that this air quality modeling configuration, in which coarse-scale meteorological fields are dynamically downscaled with a regional climate model, simulates $\mathrm{O}_{3}$, total $\mathrm{PM}_{2.5}$, and speciated $\mathrm{PM}_{2.5}$ components at a level of performance that is generally considered acceptable based on published performance metrics. Moreover, the model performance is statistically comparable to results obtained in air quality modeling studies that are driven by fine-scale meteorological observations. Therefore, when applying this downscaling methodology to simulate regional air quality in a future climate scenario, additional modeling bias strictly from this framework should not be substantial. The differing biases obtained in this study compared to other air quality modeling studies using WRF and CMAQ may be due to the use of meteorology downscaled from coarse global fields, or they may be attributable to the use of slightly different physics options and land use representations in WRF. It should be noted that the model performance obtained here likely represents an upper bound on currently attainable model performance in a downscaling application, because a GCM cannot be expected to be as accurate as a reanalysis, and the emissions data are known more precisely than any future projection.

\section{Acknowledgements}

Ozone and PM measurement data from the AQS, CSN, IMPROVE, and CASTNet field sites were acquired from the Federal Land Manager Environmental Database at http://views . cira.colostate.edu/fed/DataWizard. K.M.S. was supported by the Research Participation Program at the U.S. Environmental Protection Agency (EPA) administered by the Oak Ridge Institute for Science and Education. J.X. was supported by a National Research Council 
Research Associateship Award at the U.S. EPA under Department of Energy interagency agreement DE-SC000378 and EPA interagency agreement RW-899233260. Comments by Christian Hogrefe (EPA) and two anonymous reviewers served to strengthen this manuscript. Special thanks to Barron Henderson (University of Florida) for providing computational space to perform some of this analysis. The U.S. EPA through its Office of Research and Development collaborated in the research described here. This paper has been subjected to the Agency's administrative review and approved for publication.

Appel, K. W., Foley, K. M., Bash, J. O., Pinder, R. W., Dennis, R. L., Allen, D. J., Pickering, K., 2011. A multi-resolution assessment of the Community Multiscale Air Quality (CMAQ) model v4.7 wet deposition estimates for 2002-2006. Geosci. Model Dev. 4, 357-371.

Appel, K. W., Pouliot, G. A., Simon, H., Sarwar, G., Pye, H. O. T., Napelenok, S. L., Akhtar, F., Roselle, S. J., 2013. Evaluation of dust and trace metal estimates from the Community Multiscale Air Quality (CMAQ) model version 5.0. Geosci. Model Dev. 6, 883-899.

Bell, M. L., Goldberg, R., Hogrefe, C., Kinney, P. L., Knowlton, K., Lynn, B., Rosenthal, J., Rosenzweig, C., Patz, J. A., 2007. Climate change, ambient ozone, and health in 50 US cities. Climatic Change 82, 61-76.

Bowden, J. H., Nolte, C. G., Otte, T. L., 2013. Simulating the impact of the large-scale circulation on the regional 2-m temperature and precipitation climatology. Clim. Dyn. 40, 1903-1920.

Bowden, J. H., Otte, T. L., Nolte, C. G., Otte, M. J., 2012. Examining interior grid nudging techniques using two-way nesting in the WRF model for regional climate modeling. J. Clim. 25, 2805-2823.

Boylan, J. W., Russell, A. G., 2006. PM and light extinction model performance metrics, goals, and criteria for three-dimensional air quality models. Atmos. Environ. 40 (26), 4946-4959. 
Byun, D., Schere, K. L., 2006. Review of the governing equations, computational algorithms, and other components of the Models-3 Community Multiscale Air Quality (CMAQ) modeling system. Appl. Mech. Rev. 59, 51-77.

Carlton, A. G., Bhave, P. V., Napelenok, S. L., Edney, E. O., Sarwar, G., Pinder, R. W., Pouliot, G. A., Houyoux, M., 2010. Model representation of secondary organic aerosol in CMAQv4.7. Environ. Sci. Technol. 44, 8553-8560.

Clifton, O. E., Fiore, A. M., Correa, G., Horowitz, L. W., Naik, V., Oct. 2014. Twenty-first century reversal of the surface ozone seasonal cycle over the northeastern United States. Geophys. Res. Lett. 41 (20), 7343-7350.

Cooper, O. R., Parrish, D. D., Ziemke, J., Balashov, N. V., Cupeiro, M., Galbally, I. E., Gilge, S., Horowitz, L., Jensen, N. R., Lamarque, J.-F., Naik, V., Oltmans, S. J., Schwab, J., Shindell, D. T., Thompson, A. M., Thouret, V., Wang, Y., Zbinden, R. M., 2014. Global distribution and trends of tropospheric ozone: An observation-based review. Elementa: Science of the Anthropocene 2, 000029 .

Eder, B., Yu, S., 2006. A performance evaluation of the 2004 release of Models-3 CMAQ. Atmos. Environ. 40, 4811-4824.

European Commission, 2011. Joint Research Centre (JRC)/Netherlands Environmental Assessment Agency (PBL). Emission Database for Global Atmospheric Research (EDGAR), release version 4.2. Available at http://edgar.jrc.ec.europa.eu.

Fann, N., Brennan, T., Dolwick, P., Gamble, J. L., Ilacqua, V., Kolb, L., Nolte, C. G., Spero, T. L., Ziska, L., 2016. Air quality impacts. In: The Impacts of Climate Change on Human Health in the United States: A Scientific Assessment. U.S. Global Change Research Program, Washington, DC, Ch. 3, pp. 69-98.

Fann, N., Nolte, C. G., Dolwick, P., Spero, T. L., Curry Brown, A., Phillips, S., Anenberg, S., 2015. The geographic distribution and economic value of 
climate change-related ozone health impacts in the United States in 2030. J. Air Waste Manage. Assoc. 65, 570-580.

Fiore, A. M., Jacob, D. J., Field, B. D., Streets, D. G., Fernandes, S. D., Jang, C., 2002. Linking ozone pollution and climate change: the case for controlling methane. Geophys. Res. Lett. 29.

Fiore, A. M., Naik, V., Leibensperger, E. M., 2015. Air quality and climate connections. J. Air Waste Manage. Assoc. 65:6, 645-685.

Foley, K. M., Hogrefe, C., Pouliot, G., Possiel, N., Roselle, S. J., Simon, H., Timin, B., 2015. Dynamic evaluation of CMAQ part I: Separating the effects of changing emissions and changing meteorology on ozone levels between 2002 and 2005 in the eastern US. Atmos. Environ. 103, 247-255.

Foley, K. M., Roselle, S. J., Appel, K. W., Bhave, P. V., Pleim, J. E., Otte, T. L., Mathur, R., Sarwar, G., Young, J. O., Gilliam, R. C., Nolte, C. G., Kelly, J. T., Gilliland, A. B., Bash, J. O., 2010. Incremental testing of the Community Multiscale Air Quality (CMAQ) modeling system version 4.7. Geosci. Model Dev. 3, 205-226.

Gan, C.-M., Hogrefe, C., Mathur, R., Pleim, J., Xing, J., Wong, D., Gilliam, R., Pouliot, G., Wei, C., 2016. Assessment of the effects of horizontal grid resolution on long-term air quality trends using coupled WRF-CMAQ simulations. Atmos. Environ. 132, 207-216.

Gao, Y., Fu, J. S., Drake, J. B., Lamarque, J.-F., Liu, Y., 2013. The impact of emission and climate change on ozone in the United States under representative concentration pathways (RCPs). Atmos. Chem. Phys. 13, 9607-9621.

Gilliland, A. B., Hogrefe, C., Pinder, R. W., Godowitch, J. M., Foley, K. L., Rao, S. T., 2008. Dynamic evaluation of regional air quality models: Assessing changes in $\mathrm{O}_{3}$ stemming from changes in emissions and meteorology. Atmos. Environ. 20, 5110-5123. 
Giorgi, F., Meleux, F., 2007. Modelling the regional effects of climate change on air quality. C. R. Geosci. 339, 721-733.

Gonzalez-Abraham, R., Chung, S. H., Avise, J., Lamb, B., Salathé, Jr., E. P., Nolte, C. G., Loughlin, D., Guenther, A., Wiedinmyer, C., Duhl, T., Zhang, Y., Streets, D. G., 2015. The effects of global change upon United States air quality. Atmos. Chem. Phys. 15, 12645-12665.

Herwehe, J. A., Alapaty, K., Spero, T. L., Nolte, C. G., 2014. Increasing the credibility of regional climate simulations by introducing subgrid-scale cloudradiation interactions. J. Geophys. Res. Atmos. 119, 5317-5330.

Hogrefe, C., Hao, W., Zalewsky, E. E., Ku, J.-Y., Lynn, B., Rosenzweig, C., Schultz, M. G., Rast, S., Newchurch, M. J., Wang, L., Kinney, P. L., Sistla, G., 2011. An analysis of long-term regional-scale ozone simulations over the Northeastern United States: variability and trends. Atmos. Chem. Phys. 11, $567-582$.

Jacob, D. J., Winner, D. A., 2009. Effect of climate change on air quality. Atmos. Environ. 43, 51-63.

Kanamitsu, M., Ebisuzaki, W., Woollen, J., Yang, S.-K., Hnilo, J. J., Fiorino, M., Potter, G. L., 2002. NCEP-DOE AMIP-II Reanalysis (R-2). Bull. Amer. Meteor. Soc. 83, 1631-1643.

Katragkou, E., Zanis, P., Kioutsioukis, I., Tegoulias, I., Melas, D., Krüger, B. C., Coppola, E., 2011. Future climate change impacts on summer surface ozone from regional climate-air quality simulations over Europe. J. Geophys. Res. 116 (D22307).

Katragkou, E., Zanis, P., Tegoulias, I., Melas, D., Kioutsioukis, I., Krüger, B. C., Huszar, P., Halenka, T., Rauscher, S., 2010. Decadal regional air quality simulations over Europe in present climate: near surface ozone sensitivity to external meteorological forcing. Atmos. Chem. Phys. 10, 11805-11821. 
Kelly, J., Makar, P. A., Plummer, D. A., 2012. Projections of mid-century air-quality for North America: effects of changes in climate and precursor emissions. Atmos. Chem. Phys. 12, 5367-5390.

Lacressonnière, G., Peuch, V.-H., Arteta, J., Josse, B., Joly, M., Marécal, V., Saint Martin, D., Déqué, M., Watson, L., Dec. 2012. How realistic are air quality hindcasts driven by forcings from climate model simulations? Geosci. Model Dev. 5 (6), 1565-1587.

Leung, L. R., Gustafson, Jr., W. I., 2005. Potential regional climate change and implications to U.S. air quality. Geophys. Res. Lett. 32 (L16711).

Liu, P., Tsimpidi, A. P., Hu, Y., Stone, B., Russell, A. G., Nenes, A., 2012. Differences between downscaling with spectral and grid nudging using WRF. Atmos. Chem. Phys. 12, 3601-3610.

Menut, L., Tripathi, O. P., Colette, A., Vautard, R., Flaounas, E., Bessagnet, B., May 2013. Evaluation of regional climate simulations for air quality modelling purposes. Clim. Dyn. 40, 2515-2533.

Mesinger, F., DiMego, G., Kalnay, E., Mitchell, K., Shafran, P. C., Ebisuzaki, W., Jović, D., Woollen, J., Rogers, E., Berbery, E. H., Ek, M. B., Fan, Y., Grumbine, R., Higgins, W., Li, H., Lin, Y., Manikin, G., Parrish, D., Shi, W., 2006. North American Regional Reanalysis. Bull. Amer. Meteor. Soc. 87.

Miguez-Macho, G., Stenchikov, G. L., Robock, A., 2004. Spectral nudging to eliminate the effects of domain position and geometry in regional climate model simulations. J. Geophys. Res. 109 (D13104).

Nolte, C. G., Appel, K. W., Kelly, J. T., Bhave, P. V., Fahey, K. M., Collett, Jr., J. L., Zhang, L., Young, J. O., 2015. Evaluation of the Community Multiscale Air Quality (CMAQ) model version 5.0 against size-resolved measurements of inorganic particle composition across sites in North America. Geosci. Model Dev. 8, 2877-2892. 
Nolte, C. G., Gilliland, A. B., Hogrefe, C., Mickley, L. J., 2008. Linking global to regional models to assess future climate impacts on surface ozone levels in the United States. J. Geophys. Res. 113 (D14307).

Omrani, H., Drobinski, P., Dubos, T., 2013. Optimal nudging strategies in regional climate modelling: investigation in a Big-Brother experiment over the European and Mediterranean regions. Clim. Dyn. 41, 2451-2470.

Otte, T. L., 2008a. The impact of nudging in the meteorological model for retrospective air quality simulations. Part I: Evaluation against national observation networks. J. Appl. Met. Clim. 47, 1853-1867.

Otte, T. L., 2008b. The impact of nudging in the meteorological model for retrospective air quality simulations. Part II: Evaluating collocated meteorological and air quality observations. J. Appl. Met. Clim. 47, 1868-1887.

Otte, T. L., Nolte, C. G., Otte, M. J., Bowden, J. H., 2012. Does nudging squelch the extremes in regional climate modeling? J. Clim. 25, 7046-7066.

Otte, T. L., Pleim, J. E., 2010. The Meteorology-Chemistry Interface Processor (MCIP) for the CMAQ modeling system: updates through MCIPv3.4.1. Geosci. Model Dev. 3, 243-256.

Post, E. S., Grambsch, A., Weaver, C., Morefield, P., Huang, J., Leung, L.Y., Nolte, C. G., Adams, P., Liang, X.-Z., Zhu, J.-H., Mahoney, H., 2012. Variation in estimated ozone-related health impacts of climate change due to modeling choices and assumptions. Environ. Health Perspect. 120, 1559-1564.

Saha, S., Moorhi, S., Pan, H.-L., Wu, X., Wang, J., Nadiga, S., Tripp, P., Kistler, R., Woollen, J., Behringer, D., Liu, H., Stokes, D., Grumbine, R., Gayno, G., Wang, J., Hou, Y.-T., Chuang, H.-Y., Juang, H.-M. H., Sela, J., Iredell, M., Treadon, R., Kleist, D., van Delst, Paul, Keyser, D., Derber, J., Ek, M., Meng, J., Wei, H., Yang, R., Lord, S., van den Dool, Huug, Kumar, A., Wang, W., Long, C., Chelliah, M., Xue, Y., Huang, B., Schemm, J.-K., Ebisuzaki, W., Lin, R., Xie, P., Chen, M., Zhou, S., Higgins, W., Zou, C.-Z., 
Liu, Q., Chen, Y., Han, Y., Cucurull, L., Reynolds, R. W., Goldberg, M., 2010. The NCEP Climate Forecast System Reanalysis. Bull. Amer. Meteor. Soc. $91,1015-1057$.

Sarwar, G., Appel, K. W., Carlton, A. G., Mathur, R., Schere, K., Zhang, R., Majeed, M. A., 2011. Impact of a new condensed toluene mechanism on air quality model predictions in the US. Geosci. Model Dev. 4, 183-193.

Simon, H., Baker, K. R., Phillips, S., 2012. Compilation and interpretation of photochemical model performance statistics published between 2006 and 2012. Atmos. Environ. 61, 124-139.

Simon, H., Bhave, P. V., 2012. Simulating the degree of oxidation in atmospheric organic particles. Environ. Sci. Technol. 46, 331-339.

Simon, H., Reff, A., Wells, B., Xing, J., Frank, N., 2015. Ozone trends across the United States over a period of decreasing NOx and VOC emissions. Environ. Sci. Technol. 49, 186-195.

Skamarock, W. C., Klemp, J. B., 2008. A time-split nonhydrostatic atmospheric model for weather research and forecasting applications. J. Comput. Phys. $227,3465-3485$.

Solomon, P. A., Crumpler, D., Flanagan, J. B., Jayanty, R., Rickman, E. E., McDade, C. E., 2014. U.S. national $\mathrm{PM}_{2.5}$ chemical speciation monitoring networks-CSN and IMPROVE: Description of networks. J. Air Waste Manage. Assoc. 64 (12), 1410-1438.

Spero, T. L., Otte, M. J., Bowden, J. H., Nolte, C. G., 2014. Improving the representation of clouds, radiation, and precipitation using spectral nudging in the Weather Research and Forecasting model. J. Geophys. Res. Atmos. 199, 11682-11694.

Trail, M., Tsimpidi, A. P., Liu, P., Tsigaridis, K., Rudokas, J., Miller, P., Nenes, A., Hu, Y., Russell, A. G., 2014. Sensitivity of air quality to potential future 
climate change and emissions in the United States and major cities. Atmos. Environ. 94, 552-563.

U.S. EPA, 1998. 40 CFR Parts 51, 72, 75, and 96 Finding of Significant Contribution and Rulemaking for Certain States in the Ozone Transport Assessment Group Region for Purposes of Reducing Regional Transport of Ozone. Tech. Rep. Rule. Federal Register: 1998; No. 207, U.S. Environmental Protection Agency.

U.S. EPA, 2007. Guidance on the Use of Models and Other Analyses for Demonstrating Attainment of Air Quality Goals for Ozone, $\mathrm{PM}_{2.5}$, and Regional Haze. Tech. Rep. EPA-454/B-07-002, U.S. Environmental Protection Agency. von Storch, H., Langenberg, H., Feser, F., 2000. A spectral nudging technique for dynamical downscaling purposes. Mon. Weather Rev. 128, 3664-3673.

Weaver, C. P., Liang, X.-Z., Zhu, J., Adams, P. J., Amar, P., Avise, J., Caughey, M., Chen, J., Cohen, R. C., Cooter, E., Dawson, J. P., Gilliam, R., Gilliland, A., Goldstein, A. H., Grambsch, A., Grano, D., Guenther, A., Gustafson, W. I., Harley, R. A., He, S., Hemming, B., Hogrefe, C., Huang, H. C., Hunt, S. W., Jacob, D. J., Kinney, P. L., Kunkel, K., Lamarque, J.-F., Lamb, B., Larkin, N. K., Leung, L. R., Liao, K.-J., Lin, J.-T., Lynn, B. H., Manomaiphiboon, K., Mass, C., McKenzie, D., Mickley, L. J., O’Neill, S. M., Nolte, C., Pandis, S. N., Racherla, P. N., Rosenzweig, C., Russell, A. G., Salathé, E., Steiner, A. L., Tagaris, E., Tao, Z., Tonse, S., Wiedinmyer, C., Williams, A., Winner, D. A., Woo, J. H., Wu, S., Wuebbles, D. J., 2009. A preliminary synthesis of modeled climate change impacts on U.S. regional ozone concentrations. Bull. Amer. Meteor. Soc. 90, 1844-1863.

Wilson, A., Reich, B. J., Nolte, C. G., Spero, T. L., Hubbell, B., Rappold, A. G., 2016. Climate change impacts on projections of excess mortality at 2030 using spatially-varying ozone-temperature risk surfaces. J. Expo. Sci. Environ. Epidemiol. In press. 
Wu, S., Mickley, L. J., Leibensperger, E. M., Jacob, D. J., Rind, D., Streets, D. G., 2008. Effects of 2000-2050 global change on ozone air quality in the United States. J. Geophys. Res. 113, D06302.

Xing, J., Mathur, R., Pleim, J., Hogrefe, C., Gan, C.-M., Wong, D. C., Wei, C., Gilliam, R., Pouliot, G., 2015. Observations and modeling of air quality trends over 1990-2010 across the northern hemisphere: China, the United States and Europe. Atmos. Chem. Phys. 15, 2723-2747.

Xing, J., Pleim, J., Mathur, R., Pouliot, G., Hogrefe, C., Gan, C.-M., Wei, C., 2013. Historical gaseous and primary aerosol emissions in the United States from 1990 to 2010. Atmos. Chem. Phys. 13, 7531-7549.

Ying, Q., Kleeman, M. J., 2006. Source contributions to the regional distribution of secondary particulate matter in California. Atmos. Environ. 40, 736-752.

Yu, S., Dennis, R., Roselle, S., Nenes, A., Walker, J., Eder, B., Schere, K., Swall, J., Roberge, W., 2005. An assessment of the ability of three-dimensional air quality models with current thermodynamic equilibrium models to predict aerosol $\mathrm{NO}_{3}$. J. Geophys. Res. 110 (D07S13).

Yu, S., Eder, B., Dennis, R., Chu, S.-H., Schwartz, S. E., 2006. New unbiased symmetric metrics for the evaluation of air quality models. Atmos. Sci. Lett. 7, 26-34.

Zanis, P., Katragkou, E., Tegoulias, I., Poupkou, A., Melas, D., Huszar, P., Giorgi, F., 2011. Evaluation of near-surface ozone in air quality simulations forced by a regional climate model over Europe for the period 1991-2000. Atmos. Environ. 45, 6489-6500. 
Table 1: Metrics used in this study for evaluation of model performance for $\mathrm{O}_{3}$ (MB, ME) and PM (MFB, MFE).

\begin{tabular}{ll}
\hline Metric & Equation $^{\mathrm{a}}$ \\
\hline Mean Bias & $\mathrm{MB}=\frac{1}{N} \sum\left(M_{i}-O_{i}\right)$ \\
Mean Error & $\mathrm{ME}=\frac{1}{N} \sum\left|M_{i}-O_{i}\right|$ \\
Mean Fractional Bias & $\mathrm{MFB}=\frac{2}{N} \sum \frac{M_{i}-O_{i}}{M_{i}+O_{i}} \times 100$ \\
Mean Fractional Error & $\mathrm{MFE}=\frac{2}{N} \sum \frac{\left|M_{i}-O_{i}\right|}{M_{i}+O_{i}} \times 100$ \\
MFB Goal & $\mathrm{MFB} \leq \pm 170 e^{-\left(\overline{M_{i}}+\overline{O_{i}}\right)}+30$ \\
MFE Goal & $\mathrm{MFE} \leq 150 e^{-\frac{2}{3}\left(\overline{M_{i}}+\overline{O_{i}}\right)}+50$ \\
MFB Criteria & $\mathrm{MFB} \leq \pm 140 e^{-\left(\overline{M_{i}}+\overline{O_{i}}\right)}+60$ \\
MFE Criteria & $\mathrm{MFE} \leq 125 e^{-\frac{2}{3}\left(\overline{M_{i}}+\overline{O_{i}}\right)}+75$ \\
\hline
\end{tabular}

${ }^{a} \mathrm{O}_{i}$ are observed $\mathrm{O}_{3}$ or PM values; $M_{i}$ are modeled values for the corresponding grid cell and time period; sums are taken across all sites for a given network and across all days for a given period.

${ }^{b}$ Goal and criteria definitions from Boylan and Russell (2006); $\overline{M_{i}}$ and $\overline{O_{i}}$ denote mean $\mathrm{PM}$ concentrations in $\mu \mathrm{g} \mathrm{m}^{-3}$. 
Table 2: Seasonal bias (ppb) of modeled 25th percentile, median, and 75th percentile MDA8 $\mathrm{O}_{3}$ compared to the AQS network. Mean is expressed as the average of each absolute value. CV $=$ coefficient of variation.

\begin{tabular}{ccccccccccccc}
\hline \multirow{2}{*}{ Year } & 25th & $\begin{array}{c}\text { MAM } \\
\text { median }\end{array}$ & 75th & 25th & $\begin{array}{c}\text { JJA } \\
\text { median }\end{array}$ & 75 th & 25 th & $\begin{array}{c}\text { SON } \\
\text { median }\end{array}$ & 75 th & 25th & $\begin{array}{c}\text { DJF } \\
\text { median }\end{array}$ & 75 th \\
\hline 2000 & 3.8 & 2.2 & 0.6 & 10.8 & 11.3 & 10.4 & 12.1 & 11.5 & 11.0 & 10.0 & 8.3 & 5.5 \\
2001 & 1.5 & 0.2 & -0.3 & 9.7 & 10.3 & 9.9 & 11.3 & 10.2 & 9.4 & 10.0 & 7.9 & 5.3 \\
2002 & 2.1 & 0.8 & 0.5 & 9.5 & 9.0 & 7.1 & 12.8 & 11.3 & 10.3 & 8.7 & 7.1 & 4.7 \\
2003 & 3.0 & 0.7 & -0.1 & 9.9 & 10.2 & 9.8 & 11.1 & 10.8 & 9.5 & 8.2 & 6.2 & 4.6 \\
2004 & 2.2 & 0.4 & -0.8 & 10.4 & 10.5 & 9.6 & 12.9 & 11.4 & 10.4 & 9.1 & 7.1 & 4.2 \\
2005 & 1.2 & -0.3 & -1.5 & 11.1 & 10.5 & 9.1 & 11.9 & 10.9 & 9.7 & 9.2 & 6.9 & 4.7 \\
2006 & 1.2 & -0.2 & -1.3 & 9.2 & 8.3 & 7.2 & 11.0 & 10.9 & 10.7 & 9.2 & 6.9 & 4.3 \\
2007 & 1.9 & 0.7 & -0.7 & 10.1 & 9.0 & 8.0 & 12.4 & 11.6 & 9.7 & 8.0 & 6.6 & 4.9 \\
2008 & -0.3 & -2.0 & -3.6 & 8.4 & 7.3 & 6.4 & 12.4 & 11.7 & 10.1 & 8.1 & 6.1 & 4.2 \\
2009 & 1.0 & -1.3 & -2.6 & 10.1 & 10.0 & 9.9 & 12.9 & 11.3 & 10.0 & 7.4 & 5.6 & 3.7 \\
2010 & 2.0 & 0.5 & -0.8 & 10.2 & 10.3 & 9.5 & 9.7 & 8.3 & 7.0 & 5.9 & 4.7 & 3.4 \\
\hline $\mid$ mean $\mid$ & 1.8 & 0.9 & 1.2 & 10.0 & 9.7 & 8.8 & 11.9 & 10.9 & 9.8 & 8.5 & 6.7 & 4.5 \\
Std.Dev. & 0.98 & 0.70 & 1.07 & 0.75 & 1.16 & 1.36 & 1.00 & 0.96 & 1.06 & 1.20 & 1.01 & 0.64 \\
CV & 0.53 & 0.82 & 0.90 & 0.08 & 0.12 & 0.15 & 0.08 & 0.09 & 0.11 & 0.14 & 0.15 & 0.14 \\
\hline
\end{tabular}


Table 3: Annual model performance statistics for $\mathrm{MDA} 8 \mathrm{O}_{3}$ computed only using days on which observations exceed a specified threshold

\begin{tabular}{ccccccccccccccc}
\hline Threshold & Metric & Units & 2000 & 2001 & 2002 & 2003 & 2004 & 2005 & 2006 & 2007 & 2008 & 2009 & 2010 & Total \\
\hline $0 \mathrm{ppb}$ & $\mathrm{MB}$ & $\mathrm{ppb}$ & 8.0 & 7.1 & 6.7 & 7.1 & 7.3 & 6.8 & 6.6 & 6.9 & 5.8 & 6.9 & 6.2 & 6.8 \\
$0 \mathrm{ppb}$ & $\mathrm{ME}$ & $\mathrm{ppb}$ & 11.5 & 11.1 & 11.0 & 11.1 & 10.9 & 10.6 & 10.2 & 10.1 & 9.9 & 10.2 & 9.3 & 10.5 \\
$0 \mathrm{ppb}$ & $\mathrm{MFB}$ & percent & 20.0 & 17.4 & 16.9 & 16.8 & 18.6 & 16.6 & 16.1 & 16.6 & 15.0 & 17.7 & 14.9 & 16.9 \\
$0 \mathrm{ppb}$ & $\mathrm{MFE}$ & percent & 26.9 & 25.1 & 25.0 & 24.8 & 25.9 & 24.0 & 23.4 & 23.0 & 23.2 & 24.7 & 21.2 & 24.3 \\
$0 \mathrm{ppb}$ & $\mathrm{n}$ & - & 298160 & 287162 & 298858 & 274813 & 274142 & 277290 & 317105 & 322632 & 329276 & 333769 & 319170 & 3332377 \\
\hline $60 \mathrm{ppb}$ & $\mathrm{MB}$ & $\mathrm{ppb}$ & -0.1 & 0.0 & -1.0 & -0.7 & -2.2 & -0.8 & -0.8 & -1.2 & -3.9 & -1.8 & -1.4 & -1.2 \\
$60 \mathrm{ppb}$ & $\mathrm{ME}$ & $\mathrm{ppb}$ & 10.0 & 10.3 & 10.8 & 10.2 & 9.7 & 9.5 & 9.1 & 8.8 & 9.8 & 9.8 & 8.3 & 9.7 \\
$60 \mathrm{ppb}$ & $\mathrm{MFB}$ & percent & -1.1 & -1.1 & -2.3 & -1.9 & -4.4 & -2.2 & -2.3 & -2.6 & -6.9 & -4.1 & -3.0 & -2.7 \\
$60 \mathrm{ppb}$ & $\mathrm{MFE}$ & percent & 14.2 & 14.5 & 14.9 & 14.6 & 14.4 & 13.7 & 13.3 & 12.9 & 15.0 & 14.8 & 12.5 & 14.1 \\
$60 \mathrm{ppb}$ & $\mathrm{n}$ & - & 52499 & 53231 & 57180 & 48400 & 34830 & 50546 & 50294 & 52955 & 41527 & 26169 & 36342 & 503923 \\
\hline $70 \mathrm{ppb}$ & $\mathrm{MB}$ & $\mathrm{ppb}$ & -3.4 & -2.9 & -4.2 & -4.3 & -5.8 & -3.9 & -3.1 & -4.7 & -7.5 & -4.5 & -4.2 & -4.2 \\
$70 \mathrm{ppb}$ & $\mathrm{ME}$ & $\mathrm{ppb}$ & 10.6 & 10.9 & 11.5 & 11.3 & 11.1 & 10.3 & 10.0 & 9.9 & 11.9 & 11.0 & 10.0 & 10.8 \\
$70 \mathrm{ppb}$ & $\mathrm{MFB}$ & percent & -5.2 & -4.8 & -6.2 & -6.5 & -8.9 & -6.1 & -5.0 & -7.1 & -11.0 & -7.0 & -6.6 & -6.4 \\
$70 \mathrm{ppb}$ & $\mathrm{MFE}$ & percent & 13.8 & 14.1 & 14.6 & 14.7 & 15.2 & 13.8 & 13.2 & 13.4 & 16.4 & 14.9 & 13.6 & 14.2 \\
$70 \mathrm{ppb}$ & $\mathrm{n}$ & - & 22456 & 22737 & 28654 & 19059 & 11421 & 19827 & 17676 & 18632 & 12313 & 6680 & 8663 & 188118 \\
\hline
\end{tabular}



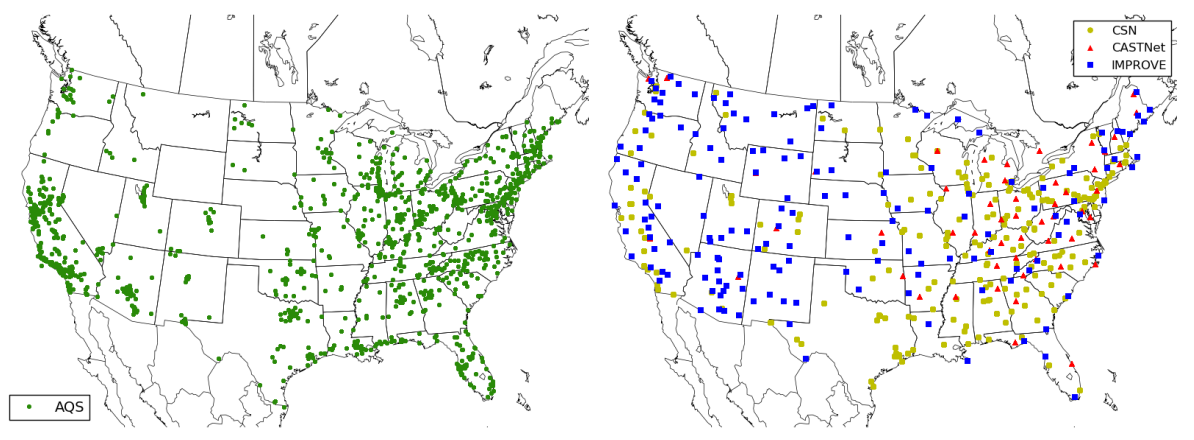

Figure 1: Locations of $\mathrm{O}_{3}$ AQS sites (green) and $\mathrm{PM}_{2.5}$ CSN (gold), CASTNet (red), and IMPROVE (blue) sites. 


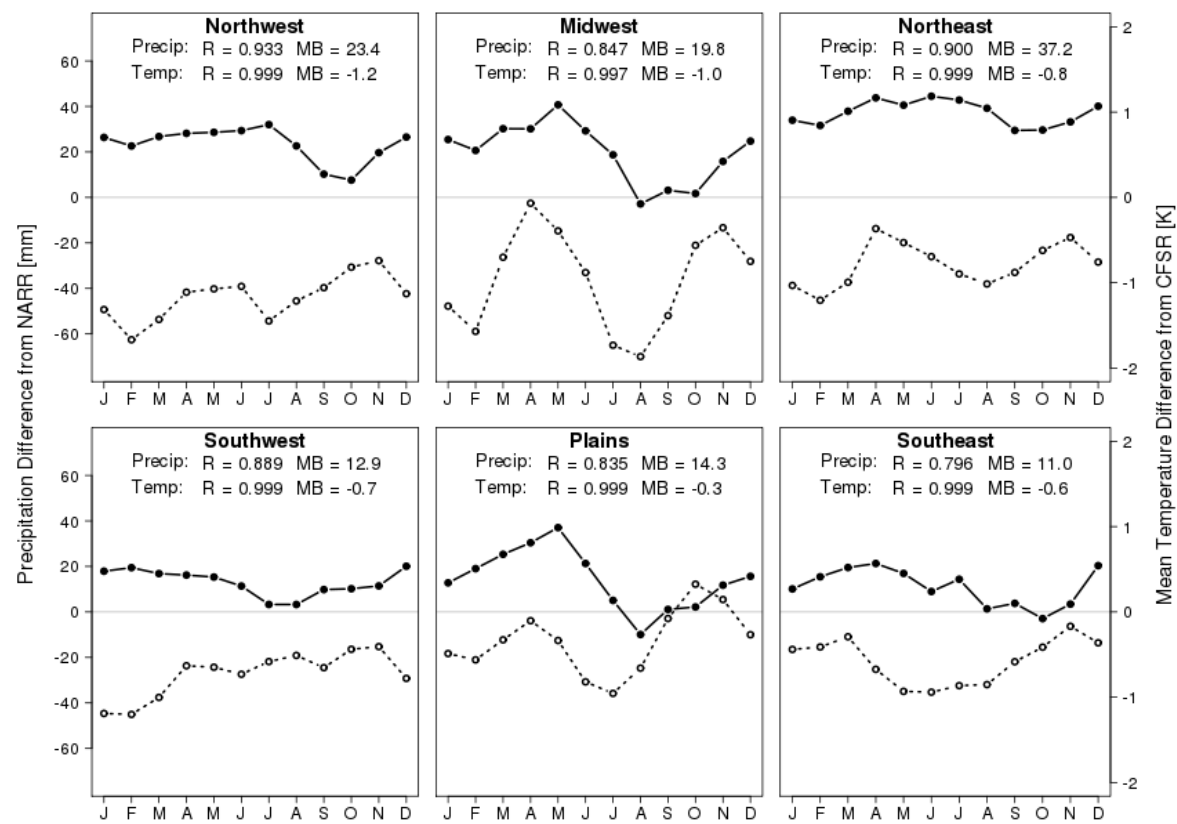

Figure 2: Monthly area-averaged precipitation difference $(\mathrm{mm})$ from NARR (solid line) and monthly area-averaged $2-m$ temperature difference (K) from CFSR (dotted line) for the WRF simulation for 2000-2010. Correlation coefficient ("R") and mean bias ("MB") are provided for average monthly precipitation with respect to NARR and for average monthly 2-m temperature with respect to CFSR. Regions are as defined in Spero et al. (2014). 

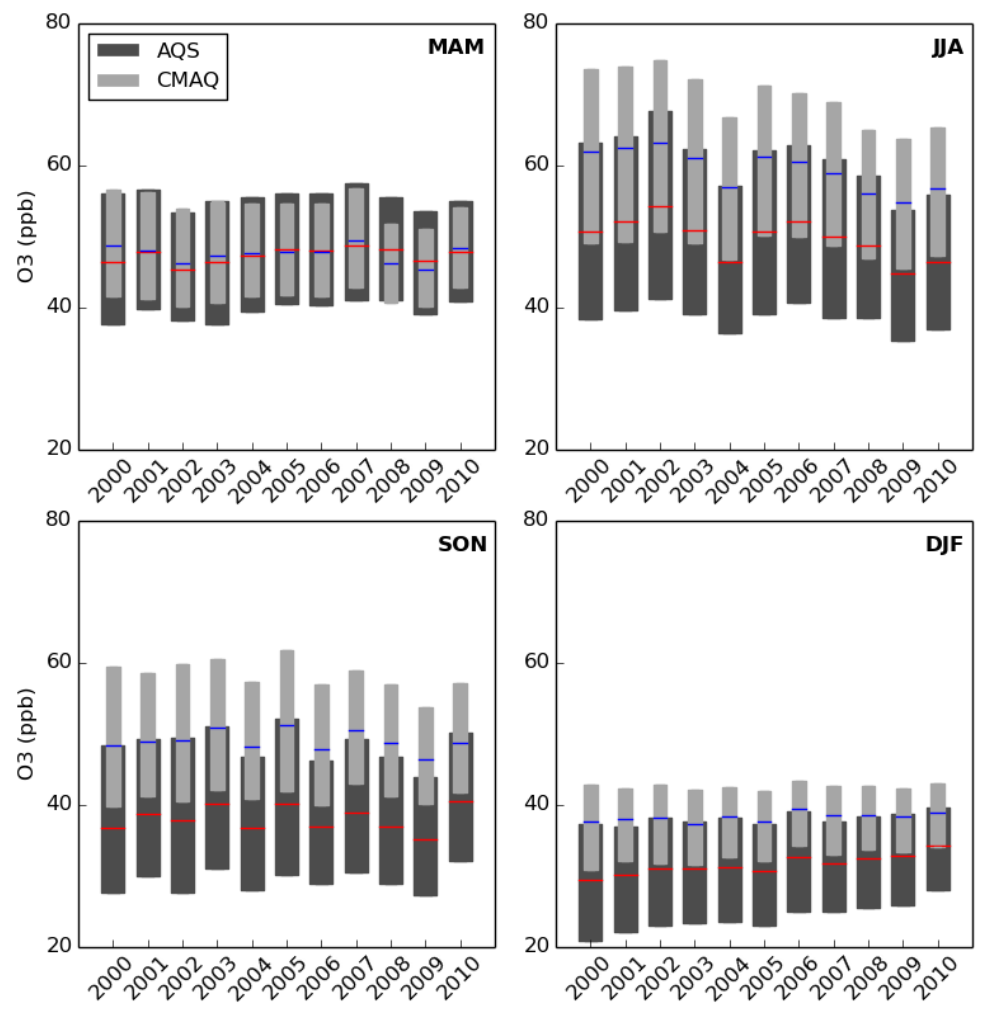

Figure 3: Seasonal distributions of MDA8 $\mathrm{O}_{3}$ at AQS sites, where "MAM" is March-AprilMay, "JJA" is June-July-August, "SON" is September-October-November, and "DJF" is December-January-February of the same year. Dark boxes show the interquartile range (IQR; 25 th through 75 th percentiles) of the observations, and red lines are the associated medians; light boxes show the IQR of modeled mixing ratios, and blue lines are the associated medians. 

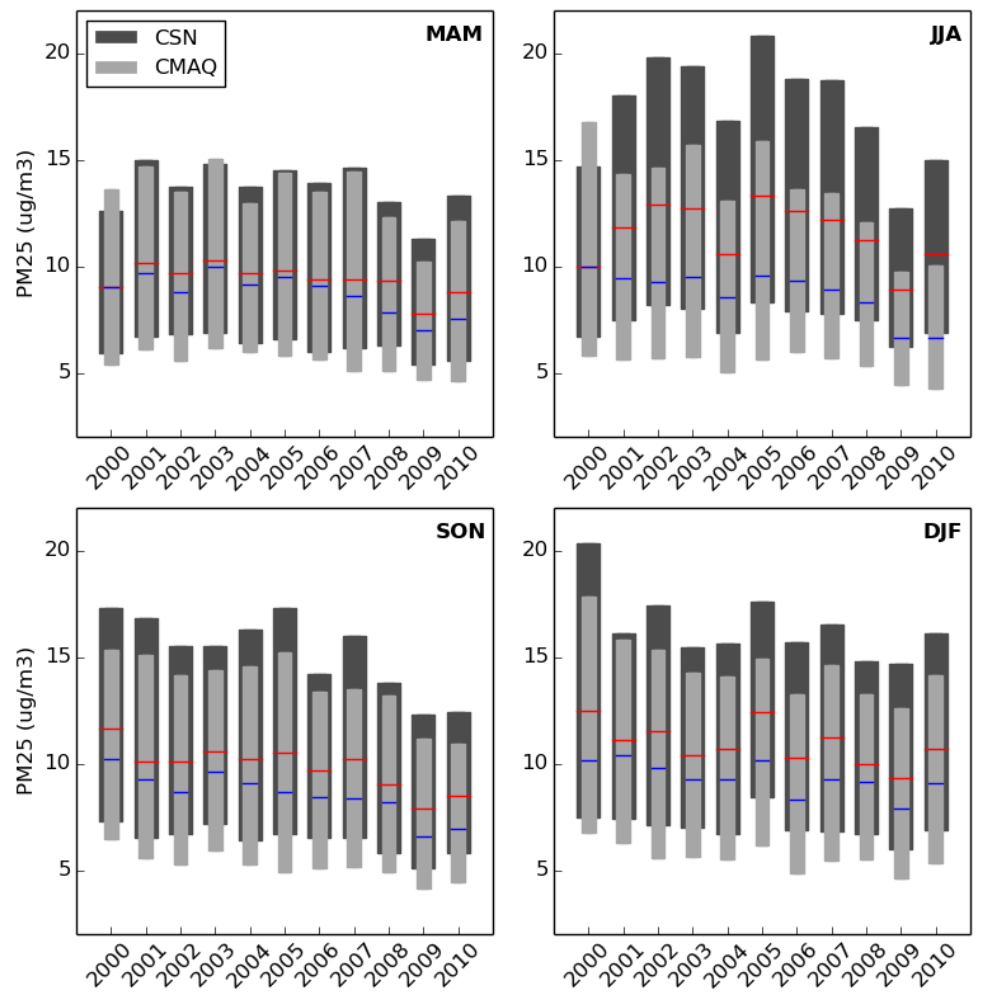

Figure 4: Seasonal distributions of total $\mathrm{PM}_{2.5}$ concentrations at CSN sites. Dark boxes show the IQR of the observations, and red lines are the associated medians; light boxes show the IQR of modeled concentrations, and blue lines are the associated medians. 

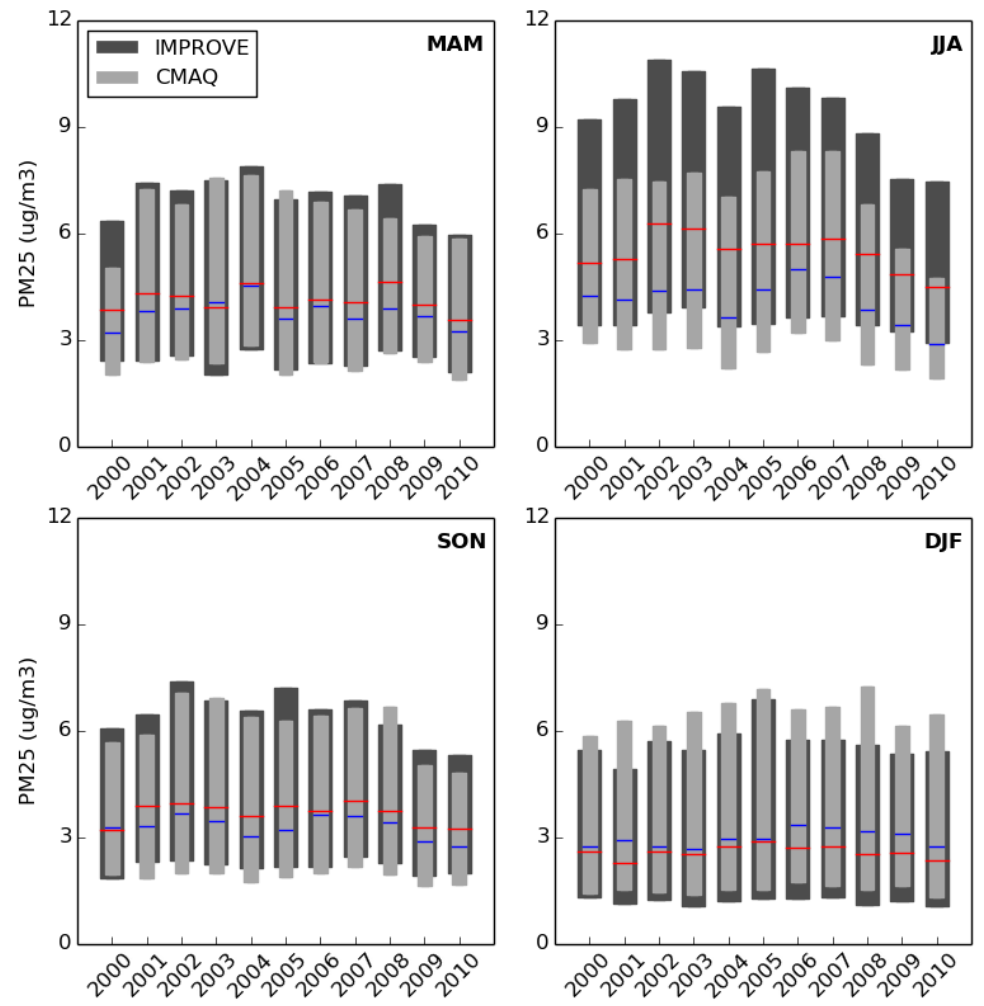

Figure 5: Seasonal distributions of total $\mathrm{PM}_{2.5}$ at IMPROVE sites. Dark boxes show the IQR of the observations, and red lines are the associated medians; light boxes show the IQR of modeled concentrations, and blue lines are the associated medians. 

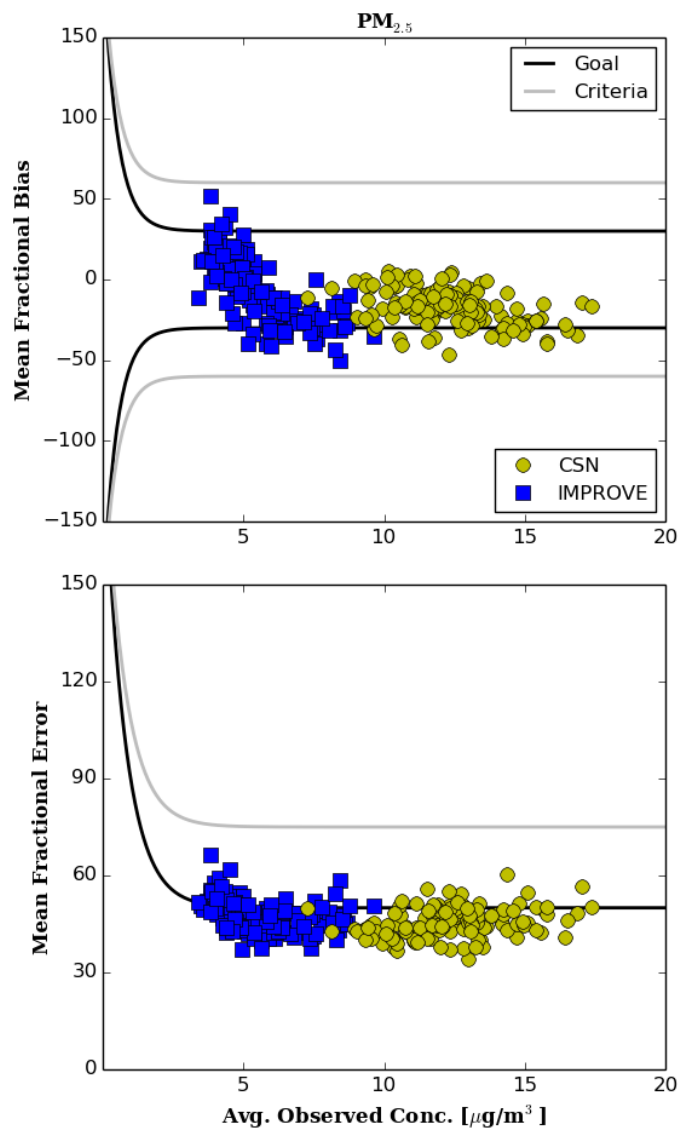

Figure 6: Total $\mathrm{PM}_{2.5}$ mean fractional bias (top) and mean fractional error (bottom) calculated for each month from 2000 to 2010, compared to the Boylan and Russell (2006) goal and criteria performance curves described in Table 1. 

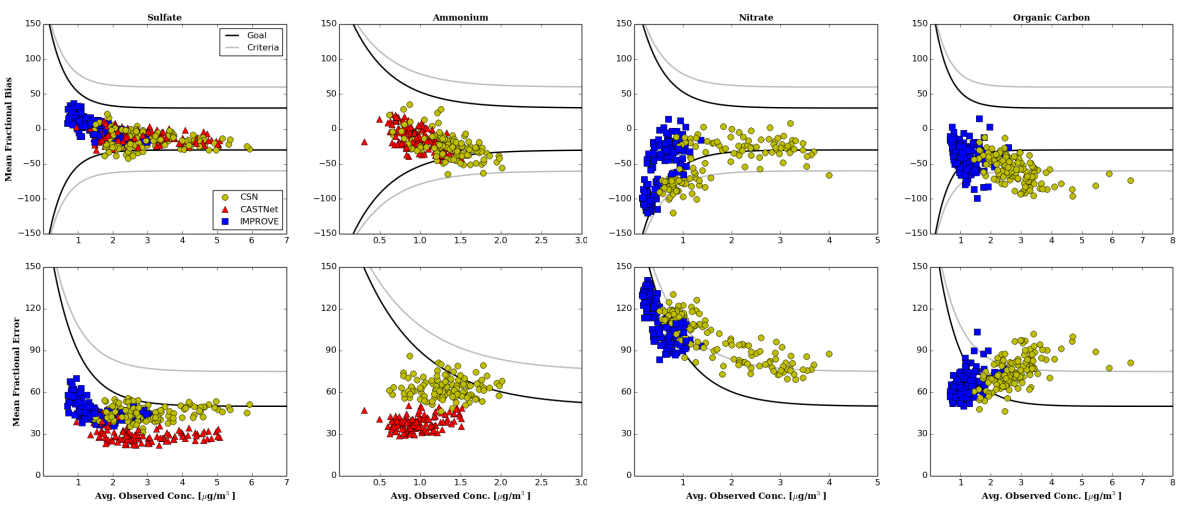

Figure 7: Speciated $\mathrm{PM}_{2.5}$ mean fractional bias (top) and mean fractional error (bottom) calculated for each month from 2000 to 2010, compared to the Boylan and Russell (2006) goal and criteria performance curves described in Table 1. 

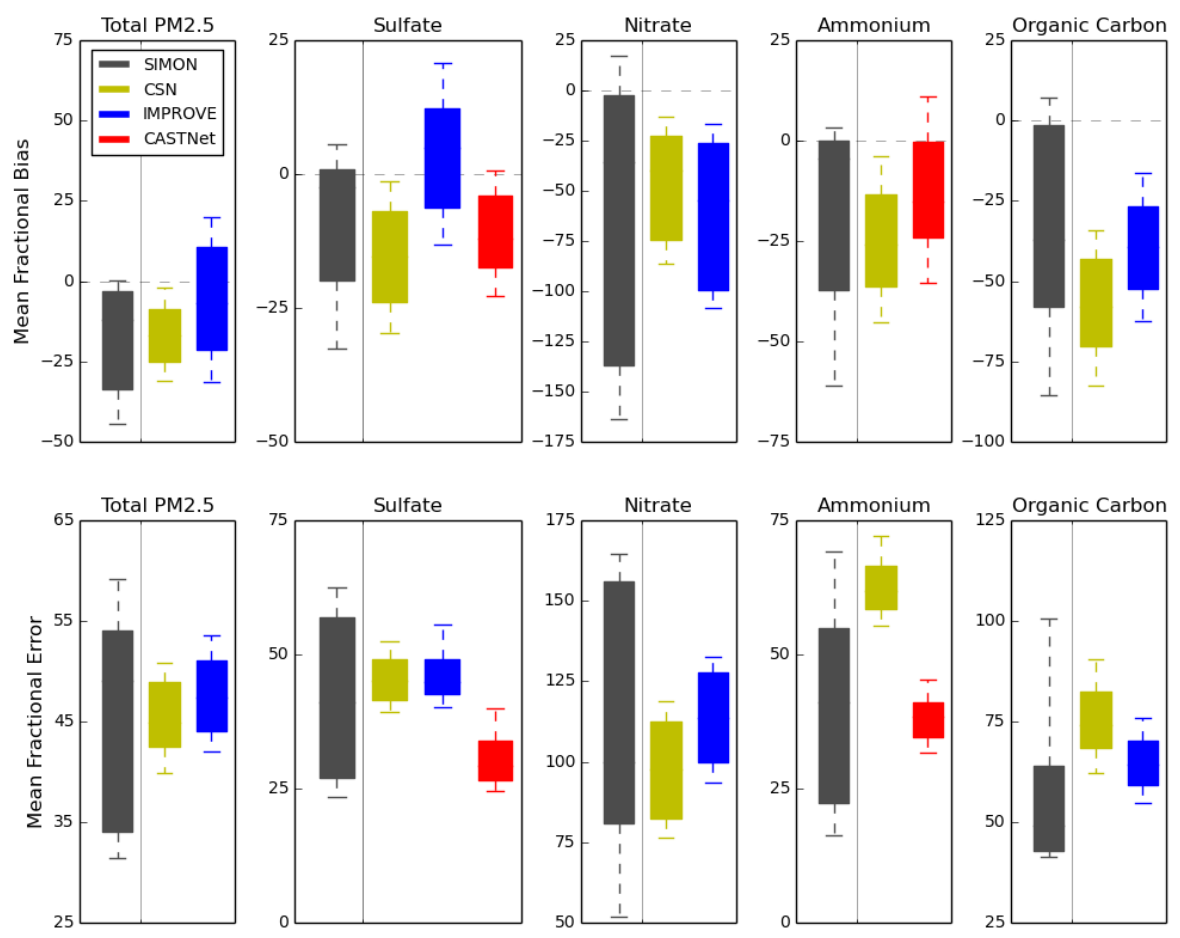

Figure 8: Modeled fractional bias (top) and fractional error (bottom) in $\mathrm{PM}_{2.5}$ and its constituents for 2000-2010, grouped by observation network and compared to the compilation study of Simon et al. (2012). The bars represent the IQR of each respective dataset and the whiskers extend to the 10th and 90th percentiles. 